\title{
Article \\ Perceived Accessibility of Public Transport as a Potential Indicator of Social Inclusion
}

\author{
Katrin Lättman *, Margareta Friman and Lars E. Olsson \\ SAMOT/CTF-Service Research Center \& Department of Social and Psychological Studies, Karlstad University, 65188 \\ Karlstad, Sweden; E-Mails: katrin.lattman@kau.se (K.L.), margareta.friman@kau.se (M.F.), lars.e.olsson@kau.se (L.E.O.) \\ * Corresponding author
}

Submitted: 16 October 2015 | Accepted: 19 January 2016 | Published: 7 June 2016

\begin{abstract}
Perceived accessibility has been acknowledged as an important aspect of transport policy since the 70s. Nevertheless, very few empirical studies have been conducted in this field. When aiming to improve social inclusion, by making sustainable transport modes accessible to all, it is important to understand the factors driving perceived accessibility. Unlike conventional accessibility measures, perceived accessibility focuses on the perceived possibilities and ease of engaging in preferred activities using different transport modes. We define perceived accessibility in terms of how easy it is to live a satisfactory life with the help of the transport system, which is not necessarily the same thing as the objective standard of the system. According to previous research, perceived accessibility varies with the subjectively-rated quality of the mode of transport. Thus, improvements in quality (e.g. trip planning, comfort, or safety) increase the perceived accessibility and make life easier to live using the chosen mode of transport. This study $(n=750)$ focuses on the perceived accessibility of public transport, captured using the Perceived Accessibility Scale PAC (Lättman, Olsson, \& Friman, 2015). More specifically, this study aims to determine how level of quality affects the perceived accessibility in public transport. A Conditional Process Model shows that, in addition to quality, feeling safe and frequency of travel are important predictors of perceived accessibility. Furthermore, elderly and those in their thirties report a lower level of perceived accessibility to their day-to-day activities using public transport. The basic premise of this study is that subjective experiences may be as important as objective indicators when planning and designing for socially inclusive transport systems.
\end{abstract}

\section{Keywords}

perceived accessibility; public transport; social exclusion; social inclusion; subjective well-being; transport planning

\section{Issue}

This article is part of the issue "Transport Policy and Social Inclusion", edited by Miriam Ricci, Graham Parkhurst and Juliet Jain (University of the West of England, UK).

(C) 2016 by the authors; licensee Cogitatio (Lisbon, Portugal). This article is licensed under a Creative Commons Attribution 4.0 International License (CC BY).

\section{Introduction}

Facing a future with ageing populations and an urging need for a sustainable development in transportation (Banister, 2008; United Nations, 2015), it now seems more important than ever to gather forces towards an inclusive sustainable transportation system that can offer high accessibility for all, including the disabled, those with physical or social impairments, or those who are not so young and able anymore.

It has been established that accessibility is positively connected to several travel outcomes, such as wellbeing (Parkhurst \& Meek, 2014) and transport-related social inclusion (Farrington, 2007; Stanley, Stanley, Vella-Brodrick, \& Currie, 2010) and that insufficient accessibility may cause social exclusion (Hui \& Habib, 2014; Kenyon, 2011), proposing that accessibility is a key issue for research development on social inclusion and 
sustainable transport planning. Up until now however, measuring accessibility has been limited to objective measures such as travel time or distance, not capturing the perceived accessibility of individuals or certain groups of people, limiting the usefulness of the link between accessibility and social inclusion since the measured accessibility may not capture the reality (Curl, Nelson, \& Anable, 2011). This gap in measuring accessibility has been pointed out by researchers for years, urging for the inclusion of subjective accessibility (Budd \& Mumford, 2006; Curl et al., 2011; Farrington, 2007; Handy \& Niemeier, 1997; Stanley \& VellaBrodrick, 2009; van Wee \& Geurs, 2011), but up until now not much has been done. In 2015, we developed a quantifiable measurement for perceived accessibility in public transport, the Perceived Accessibility Scale (Lättman et al., 2015). Perceived accessibility is based on individual assessments of accessibility, rather than on objective estimates, and in the current study, the work is continued by further exploring perceived accessibility in relation to transport quality, safety, travel frequency, and age, looking for significant determinants.

\subsection{Accessibility}

A popular and well-used definition of accessibility is "the extent to which land-use and transport systems enable (groups of) individuals to reach activities or destinations by means of a (combination of) transport mode(s)." founded by Geurs and Ritsema van Eck (2001). As the definition implies, accessibility has conventionally been closely linked to the ability to move (e.g., mobility), and more specifically defined and operationalized through objective measurements such as travel time, distance to train station, or distance and travel time to a selection of destinations. This is risky, not only because of the lack of individual perspectives, but also as targeting increased mobility for certain groups of individuals in a society, may inadvertently decrease the mobility for other groups whose mobility-preferences we are not aware of (e.g. by moving bus-stops, changing time-tables) and they may experience social exclusion (Kenyon \& Lyons, 2003). However, the focus in transport planning has of late shifted from mobility to accessibility (Halden, 2011; Preston \& Rajé, 2007; Qviström, 2015) widening the scope of focus, but still not including individual or group perspectives. Individual characteristics are known to influence a person's level of access to transport modes in terms of needs, opportunities and abilities that set temporal-spatial constraints (e.g. age and physical condition) (Geurs \& Van Wee, 2004). Budd and Mumford (2006) found several flaws in the common generalization that high (area) accessibility equals high individual accessibility; meaning that objective generalizations do not take into consideration awareness of opportunities, ability to use, personal relevance or interest.

Accessibility to important activities is influential for subjective wellbeing (De Vos, Schwanen, Van Acker, \& Witlox, 2013; Olsson, Gärling, Ettema, Friman, \& Fujii, 2013; Parkhurst \& Meek, 2014). Not having full access to different travel modes may thus exclude people from various activities and lower their subjective wellbeing. Many researchers are aware of this link; however, looking past proposed solutions to reduce travel hardships with the aim of increasing accessibility in a cost-effective manner (Martens, 2012), or using objective determinants as the basis for accessibility evaluations (Bekiaris \& Gaitanidou, 2012; Kryvobokov \& Bouzouina, 2014; Lucas, 2012; van Wee \& Geurs, 2011), we argue that, in order to improve social inclusion and wellbeing, we need to understand what drives perceived accessibility and use this knowledge to make it easier for people to be a part of society. Thus, perceived accessibility to social activities and friends cannot be evaluated using conventional accessibility measures, since these choices and routes are highly individual.

We define perceived accessibility in terms of how easy it is to live a satisfactory life using the transport system which includes accessibility while using the transport system per se, ease of getting to the transport system, and the perceived possibilities and ease to live the life one wants with help of the transport system. We argue that, what needs to be evaluated in order to improve accessibility is whether or not the travelers themselves (or potential travelers) perceive the transport system as accessible, and something they are able to benefit from, and also to explore what determines the perceived accessibility.

\subsection{Social Inclusion and Accessibility}

Preston and Rajé (2007), influenced by Sen (2000) established a conceptualization describing social exclusion as caused by an absence of access to social opportunities, rather than a lack of opportunities per se. In line with this work The Social Exclusion Unit (2004) has worked from the perspective that the main solution for transport-based social exclusion is accessibility planning. More specifically, they state that aiming for an increased accessibility to services and key locations by the transport services is essential in preventing social exclusion. Following this, work by Kenyon and Lyons (2003) and Currie and Stanley (2008) link social exclusion to a lack of access to social opportunities in the UK and Australia, respectively. Kenyon (2011, p. 764) more recently claims that "a lack of access to opportunities/social networks necessary for inclusion in the society can cause social exclusion". Research by Farrington and Farrington (2005), and Farrington (2007) conclude that greater accessibility is linked to greater social in- 
clusion and social dimensions of sustainability. They also claim that by targeting accessibility we force transport planners in different areas to interact toward a common policy goal (Farrington \& Farrington, 2005). More recently it has been established that people who experience the transport system as accessible also experience less social exclusion, and a key factor determining experienced accessibility is frequency of services (Hui \& Habib, 2014). Another study has found positive links between public transport usage and social inclusion, "possibly suggesting that public transport is assisting people to be included" (Stanley et al., 2010, p. 283).

\subsection{Quality}

Since previous research has revealed relations between (some) public transport quality attributes and accessibility (Redman, Friman, Gärling, \& Hartig, 2013) there is reason to believe that additional quality attributes also are important to accessibility. A large number of attributes have been proposed in attempting to define public transport quality, but most commonly used quality attributes in determining conventional accessibility are travel time (including waiting time and punctuality), distance and departures (Bates, Polak, Jones, \& Cook, 2001; Friman, 2010; Hensher, Stopher, \& Bullock, 2003). A recent literature review (Redman et al., 2013) revealed that reliability is a key quality attribute of public transport service, with frequency, fare prices, and speed also being important. Other studies have shown the importance of safety/security (de Oña, de Oña, Eboli, \& Mazzulla, 2013; Friman \& Gärling, 2001), the information given to travelers (de Oña et al., 2013), the system (with supply and reliability items) including comfort/design (dell'Olio, Ibeas, Cecín, \& dell'Olio, 2011), and staff behavior (Friman \& Fellesson, 2009) on transport quality.

More recently, researchers have begun to include safety aspects in their theories on individual accessibility, e.g. holistic safety-chains from origin to destination (Bekiaris \& Gaitanidou, 2012) and women's fears while in the public transport environment (Loukaitou-Sideris, 2009). Safety refers to the emotional evaluations (feelings) of the individual (Redman et al., 2013), whereas most quality dimensions depend on cognitive evaluations.

It is generally held that we are able to affect up to $40 \%$ of our own wellbeing, by participating in daily activities (Lyubomirsky, Sheldon, \& Schkade, 2005). Unfortunately, not all of us have the ability to affect our own travel or our daily participation in activities due to insufficient accessibility, and this may lead to a form of seclusion that causes social exclusion. According to Currie and Stanley (2008) the mere risk of being socially excluded has a directly negative effect on subjective well-being. Social inclusion is dependent on the ability to use the transport system for social activities, as much as for getting to work. It is thus important to capture these aspects when measuring transport accessibility. Previous studies encompassing perceived accessibility have not been equipped with measures to quantify the results. The perceived accessibility scale (Lättman et al., 2015) was developed with the aim of capturing how easy it is to live a satisfactory life with the help of the chosen, or designated, travel mode. Without reliable measures of perceived accessibility, it is argued that evaluating and following up goals and visions regarding accessibility, from a user perspective, will be difficult, thus creating a broad and generalizable measure of perceived accessibility was needed in order to investigate or compare accessibility between different transport modes, between different groups of people, in different areas, for different purposes, or in different transport systems.

\subsection{Aim and Hypotheses}

In this study, we argue that the quality level of public transport creates prerequisites for possibilities and ease of engaging in preferred activities, and that the above-mentioned aspects-quality, safety, frequency of use, and age-affect perceived accessibility in public transport. By looking at transport service quality level in relation to perceived accessibility our hope is to reach an understanding of the driving factors of perceived accessibility. More specifically; we test the impact of perceived level of quality of the chosen transport mode, frequency of use, age and safety on perceived accessibility. We also propose that safety mediates (explains) some of the effect quality has on perceived accessibility, and that the effect of quality on perceived accessibility is moderated by (dependent on) frequency of use.

Hypothesis 1: Perceived level of quality has a direct positive effect on perceived accessibility

Hypothesis 2a: (Feelings of) safety has a direct positive effect on perceived accessibility

Hypothesis $\mathbf{2 b}$ : The effect of quality on perceived accessibility is positively mediated by safety

The above hypotheses 1 and 2a are strengthened by a study (Lotfi \& Koohsari, 2009) suggesting that a low level of perceived accessibility is due to people feeling unsafe and experiencing low quality in terms of comfort. We also believe that the effect of quality on perceived accessibility is positively mediated by the individual's feelings and perceptions of safety (2b). In other words we think that part of the relationship between perceived quality and perceived accessibility can be explained by safety.

It is furthermore hypothesized that frequency of use, as in how frequently the individual travels using 
the assessed transport mode, directly effects perceived accessibility (3a), but also moderates the effect of quality on perceived accessibility (3b). More specifically, it is suggested that more frequent travelers put more emphasis on aspects of quality, and the effect of quality on accessibility is higher for frequent travelers. This also implicitly indicates that the effect of quality on accessibility will be smaller in groups of less frequent travelers. Finally, we investigate whether age affects perceived accessibility proposing that age has a negative relationship with perceived accessibility, meaning that the older one gets, the lower the perceived accessibility, in line with previous research on age and accessibility (Sundling, Berglund, Nilsson, Emardson, \& Pendrill, 2014).

Hypothesis 3a: Frequency of use has a direct positive effect on perceived accessibility Hypothesis 3b: The effect of quality on perceived accessibility is moderated by (conditional on) frequency of use

Hypothesis 4: Age has a direct negative effect on perceived accessibility

In summary, this study will increase our knowledge of different aspects associated with perceived accessibility in public transport. Next section provides a description of the method and data used for analysis. The results of a conditional process model, applied in order to examine the proposed relations, will be discussed. Finally, we will draw some conclusions and discuss some avenues for future research.

\section{Method}

\subsection{Participants}

The data was collected in the City of Karlstad, a middle sized town in Sweden (90.000 inhabitants) on three occasions; June 2013, November 2013, and May 2014. Each data collection went on for three subsequent days, between 8.00 am and 5.00 pm approximately. The 750 participants were asked to complete a questionnaire while waiting for the bus, coming from the bus or sitting on the bus. People located in the town bus-transfer areas or on the bus at the time of the collection were asked to participate. The questionnaire was distributed on a clipboard and took approximately five minutes to complete. The participants were offered a lottery ticket with a chance of winning a 30 day bus pass. As this was the first approach to studying links between perceived quality occurring at different stages of travel (before, during), and perceived accessibility this initial data collection involved only bus-travelers. The participants were aged between 16 and 87, $M=27.60, S D=13.47$ (61 \% women and $39 \%$ men) the majority were on their way to or from work, school or social activities (visiting friends or family, shopping, sports etc.).

\subsection{Survey and Instruments}

The survey consisted of three sections. Part one included the quality attributes capturing the quality dimensions, part two included the perceived accessibility items, and part three included background data. The background data consisted of questions about frequency of travel by public transport (less than once a month, once a month, once a week, or daily), gender, and age.

\subsubsection{The Perceived Accessibility Scale}

The Perceived Accessibility Scale (PAC) is an aggregate measure of perceived accessibility (Lättman et al., 2015), developed for use in transportation. It is easy to use and distribute; due to its compactness and interpretable outcome, making it useful not only within research, but also as a tool on the policy and planning levels. The PAC consists of four items that measure the ease of travel ("It's easy to do [daily] activities with public transport"), the ability to live the life one wants ("If public transport was my only mode of travel, l'd be able to continue living the way I want"), and accessibility to activities ("It's possible to do the activities I prefer with public transport" and "Access to my preferred activities is satisfying with public transport"). These items capture the overall level of perceived accessibility on self-assessment scales, from 1-7 (1 = I disagree 7 $=$ I completely agree) which are then indexed into an overall accessibility score, based on previous psychometric findings (Lättman et al., 2015). Cronbach's Alpha for this sample revealed a satisfying reliability of $\alpha=$ $.88(\mathrm{~N}=747)$.

\subsubsection{Quality Dimensions}

A set of items was devised to measure the perceived quality level of the public transport services (see Table 1). The items were intended to tap into different, but complementary, aspects of quality. For each item, the respondents checked a seven-point scale ranging from "very dissatisfied" (1) to "very satisfied" (7). They were asked to rate these items regarding trips with the local bus company (Karlstadbuss) in general, not just the ongoing trip. Given the relations between quality aspects, and when they occur during travel, we divided the items into four quality dimensions labeled; reliability/functionality, information, courtesy/simplicity (on board), and comfort. These sub-dimensions were established psychometrically sound by a confirmatory second-order factor analysis $\left(\chi^{2}=149.69, \mathrm{df}=128, p=\right.$ $.092, \mathrm{NFI}=.977, \mathrm{CFI}=.996, \mathrm{RMSEA}=.015)$ with quality as the main construct. 


\subsubsection{Safety}

Safety represents the emotional evaluation the individual makes regarding aspects of safety connected to travel. Safety was measured using two reversed items, asking the participants to grade their level of security (I feel secure) on a 1-7 Likert-scale, and asking them to grade their usual level of distress or peace of mind (when traveling by public transport) on a continuum from 1-7 (I usually feel distressed-I usually feel calm). The correlation between the items was $r=.31$. We averaged the items to form a safety variable.

\subsection{Conditional Process Modeling}

In order to investigate the relation between overall quality level and perceived accessibility, with other predictor variables (age, frequency of use, and safety) that would also serve as a mediator (safety) and moderator (frequency of use) of the effect of quality, a conditional process model (Hayes, 2013) was deemed appropriate for the analyses. Conditional process modeling is used when the purpose is to estimate direct $(X$ to $Y$ ) and indirect (intermediate through a mediator $X$ $M-Y$ ) pathways, and how the effect of one (or more) of these depend (is conditional) on another variable, the moderator ( $X-Y$ depends on $W$ ). For a more thorough description see Hayes (2013).

\section{Results}

As the aim of this study was to examine the relationships between level of quality and perceived accessibility, a quality index was initially created from the four quality dimensions described in section 2.2.2. A conditional process analysis (Hayes, 2013) was then run to determine the relations between quality index, frequency of travel, safety, age, and perceived accessibility, with safety as a proposed mediator of quality, and frequency as a proposed moderator of quality. As a final step, a cluster analysis was performed which looked more closely at the relationship between age and perceived accessibility. Table 2 provides descriptive statistics of all the included variables, while the results of the subsequent analyses follow below.

\subsection{Quality-Index}

In order to run a combined mediation and moderation analysis (see 2.3), a quality index had to be created from the four quality dimensions. A Principal Axis Factoring analysis (Warner, 2008) was used to determine whether the four quality dimensions described in section 2.2.2 are unidimensional (Byrne, 2010; Gorsuch, 1997). This analysis extracted one factor with an eigenvalue of 2.85 , explaining $71.3 \%$ of the variance in the factor. The Kaiser-Meyer-Olkin measure revealed a multiple KMO of .82, with all individual item KMO values above .80 , putting the sampling adequacy well above the threshold of .5 (Field, 2013). The factor score coefficients were used to create the quality index in order to get a weighted relevance for the total score. A reliability analysis of the quality index revealed a satisfying Cronbach's alpha $(\alpha=.76)$, with no significant changes for item deletion. The factor loadings, factor score weights, and weighted relevance are presented in Table 3.

Table 1. Items measuring four dimensions of quality.

\begin{tabular}{llll}
\hline Reliability/Functionality & Information & Courtesy/Simplicity(on board) & Comfort \\
\hline Travel time & Mobile app & Announcements & Air quality \\
(no. of) Departures & Info on homepage & Staff attitude/behavior & Cleanliness \\
$\begin{array}{l}\text { Distance (to bus stop) } \\
\text { Trip coordination }\end{array}$ & Info at bus-stop & Info on board & Lighting \\
$\begin{array}{l}\text { Payment options } \\
\text { Punctuality }\end{array}$ & & Boarding and exiting & Noise level \\
\hline
\end{tabular}

Table 2. Sample statistics, correlations, means (M) and standard deviation (SD) for each variable in the study.

\begin{tabular}{|c|c|c|c|c|c|c|c|c|c|}
\hline Variable & 1 & 2 & 3 & 4 & 5 & 6 & 7 & $\mathbf{M}$ & SD \\
\hline 1. Age & --- & --- & --- & --- & --- & --- & --- & 27.60 & 13.47 \\
\hline 2. Frequency & $-.22 *$ & --- & --- & --- & --- & --- & --- & 2.61 & 0.68 \\
\hline 3. Reliability/Functionality & $.14^{*}$ & -.04 & --- & --- & --- & --- & --- & 26.52 & 5.26 \\
\hline 4. Comfort & $.17^{*}$ & .04 & $.64 *$ & --- & --- & --- & --- & 26.83 & 5.99 \\
\hline 5. Information & $.05^{*}$ & .00 & $.62 *$ & $.53^{*}$ & --- & --- & --- & 12.30 & 2.77 \\
\hline $\begin{array}{l}\text { 6. Courtesy/ Simplicity (on } \\
\text { board) }\end{array}$ & $.21^{*}$ & -.02 & $.66^{*}$ & $.67^{*}$ & $.59 *$ & --- & --- & 17.12 & 3.45 \\
\hline 7. Safety & .03 & .05 & $.56^{*}$ & $.61^{*}$ & $.46^{*}$ & $.54 *$ & --- & 8.76 & 1.48 \\
\hline 8. Perceived accessibility & -.07 & $.17^{*}$ & $.55^{*}$ & $.46 *$ & $.47^{*}$ & $.46^{*}$ & $.49 *$ & 5.12 & 1.34 \\
\hline
\end{tabular}

Note: $* p<.05$. 


\subsection{Conditional Process Model}

In order to examine the proposed relations, a conditional process model was used (described in 2.3). The analysis included proposed mediation of quality on perceived accessibility through safety and proposed moderation through frequency of use, using PROCESS model 5 (Hayes, 2013). The model proved significant $\left(R^{2}=.377 ; F^{(5,636)}=79.93 p<.001\right)$ and showed that quality, age, and trip frequency predict perceived accessibility (PAC) $(.050,-.012$, and .273 respectively). The effect of quality on perceived accessibility is positively mediated by safety (the safer an individual feels - the higher their PAC score) (see Figure 1).

However, contrary to our hypothesis, the impact of quality on perceived accessibility is not moderated by frequency, suggesting that the importance of quality in predicting perceived accessibility is not conditional on frequency of use.

\subsection{Cluster Analysis}

The conditional process model confirmed age as a negative predictor of perceived accessibility; however, a plot of the result indicated a curvilinear relationship. A $\mathrm{K}$-means cluster analysis was performed aimed at identifying potential subgroups in the data, looking at age and level of PAC. The clusters were calculated using an iterative process, searching for representative means in the data and assigning cases to the nearest mean.

Table 3. Factor loadings, factor score weights, and weighted relevance for the four quality dimensions* $(N=750)$.

\begin{tabular}{lllll}
\hline Quality dimensions & $\begin{array}{l}\text { Factor } \\
\text { loadings }\end{array}$ & $\begin{array}{l}\text { Factor score } \\
\text { weights }\end{array}$ & $\begin{array}{l}\text { Weighted } \\
\text { relevance in \% }\end{array}$ & $\begin{array}{l}\boldsymbol{\alpha} \text { if item } \\
\text { deleted }\end{array}$ \\
\hline Reliability/Functionality & .825 & .337 & $32 \%$ & .61 \\
Courtesy/Simplicity & .827 & .337 & $32 \%$ & .70 \\
Comfort & .778 & .242 & $21 \%$ & .66 \\
Information & .714 & .180 & $15 \%$ & .77 \\
\hline
\end{tabular}

Note: * Factor loadings $=$ The extent to which the item measurements are related to the latent construct. Factor score weights $=$ How much each dimension affects the factor score.

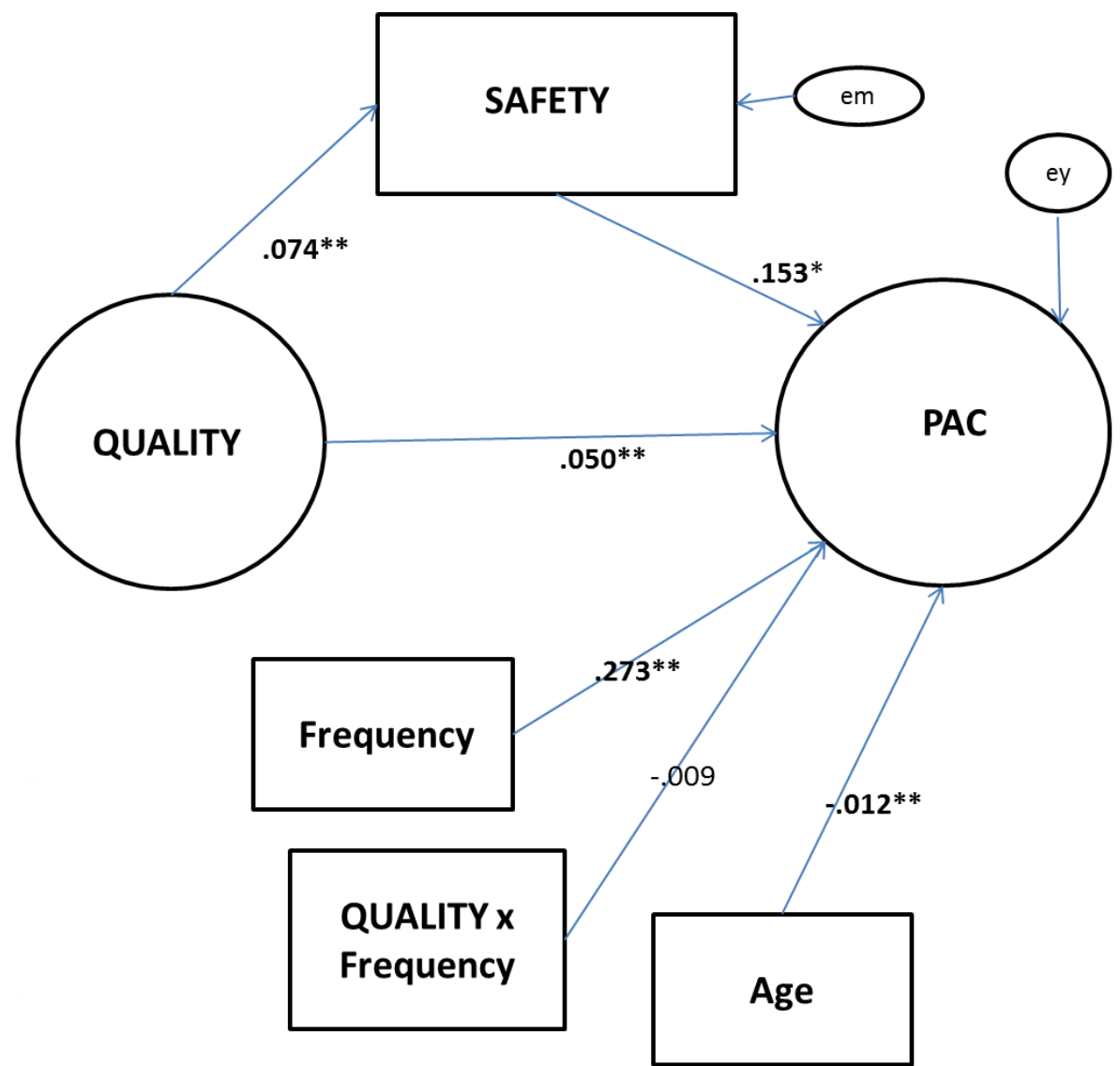

Figure 1. Conditional Process model of the effect of Quality, Safety, Frequency and Age on Perceived accessibility (PAC). $(\mathrm{N}=642)$. Note: ${ }^{*} \mathrm{p}<.005 * * \mathrm{p}<.001$ (ey and em represent measurement error in the $\mathrm{y}$ (dependent) and $\mathrm{m}$ (mediating) variables, respectively). 
Table 4. Classification of bus travelers by mean age and level of PAC (mean).

\begin{tabular}{|c|c|c|c|c|c|c|}
\hline & \multirow{2}{*}{$\begin{array}{c}\text { Cluster } 1 \\
(n=473,72 \%)\end{array}$} & \multirow{2}{*}{$\begin{array}{c}\text { Cluster } 2 \\
(n=85,13 \%)\end{array}$} & \multirow{2}{*}{$\begin{array}{c}\text { Cluster } 3 \\
(n=73,11 \%)\end{array}$} & \multirow{2}{*}{$\begin{array}{c}\text { Cluster } 4 \\
(n=22,3.5 \%)\end{array}$} & \multicolumn{2}{|c|}{ ANOVA } \\
\hline & & & & & $\mathbf{F}$ & $p$ \\
\hline Age & 21 & 34 & 52 & 68 & 2358.93 & $<.001$ \\
\hline Perceived accessibility & 5.21 & 4.77 & 5.09 & 4.82 & 2.95 & .023 \\
\hline
\end{tabular}

This process is repeated until only small differences occur when transferring cases between clusters, indicating a good fit. Several K-means analyses were run, in order to determine the preferred number of clusters, resulting in a model of 4 clusters, as displayed in Table 4. Individuals around the age of 34, and elderly (around 68), reported significantly lower levels of perceived accessibility than people in their twenties and fifties. No gender differences were observed when comparing the clusters.

\section{Discussion}

As hypothesized, our findings indicate that quality is important for perceived accessibility. Overall quality positively predicted perceived accessibility, which suggests that an increase in perceived quality will lead the users to perceive the transport mode as being more accessible, in turn making it easier for them to live the life they want, creating prerequisites for social inclusion. However, the results also show that some quality dimensions seem to contribute more than others. Specifically two quality dimensions appeared to be more important. Distance to bus stops, the availability of transport at convenient times, and flexibility and ease when buying tickets combine to make the first highly ranked dimension (Reliability/functionality) with staff attitudes and behavior, ease of getting on and off vehicles, announcements on board, and information available during travel being included in the second dimension (Courtesy/simplicity). These dimensions together make up for $64 \%$ of the weighted importance in the overall quality variable, and considering the close link between accessibility and social inclusion (Kenyon, 2011), these findings have implications for which service quality aspects that may be more important for building an inclusive sustainable transport system.

As expected, feeling safe is also important for perceived accessibility. Our findings show that perceived quality positively affects our feelings of safety, the higher the perceived quality the higher perceived safety, and that safety explains some of the effect perceived quality has on perceived accessibility. Safety also has a direct effect on perceived accessibility, not affected by perceived quality. These results imply that safety is an important predictor of perceived accessibility, both in its own right, but also as an intermediate mechanism for other accessibility determinants, such as quality dimension. This finding reminds us that it may be important not to confuse feelings of safety with other, cognitive evaluations, of the quality of the transport mode. The outcomes are in line with studies of perceived satisfaction which determine that an experience contains both emotional and cognitive evaluations (Friman, Fujii, Ettema, Gärling, \& Olsson, 2013) and also a study by Lotfi and Koohsari (2009) successfully separating safety from quality and linking these to perceived accessibility.

The proposed conditional relationship was not supported in the analysis, suggesting that the importance of quality when predicting perceived accessibility is not conditional on frequency of travel. This may be good news, since an increase in quality would affect the levels of perceived accessibility for all passengers, not only those who travel frequently. However, frequency of use itself influences perceived accessibility, indicating that more frequent users perceive the chosen transport mode as more accessible than those who travel less often.

Our results further indicate that age is important for perceived accessibility. In line with previous research on accessibility and social exclusion, we had hypothesized that elderly would experience lower levels of perceived accessibility, However, two groups turned out to experience a lower level of accessibility, elderly and people in their thirties. Relying on our definition of perceived accessibility this outcome can be explained by different quantities, and types of, activities. A Swedish study shows that the elderly (aged 58-94) experience difficulties with long distances to bus stops, stairs and level-differences at interchanges, timetables that are not synchronized, and departure times that are not suitable for their daily activities (Berg \& Levin, 2011). The other age group experiencing a low level of perceived accessibility belongs to a phase in life which is closely linked to parenting. Parenthood means a totally different activity pattern for most people, characterized by taking children to school and leisure activities. This group experiences the lowest level of perceived accessibility, an unexpected and important finding considering the ongoing development towards sustainable transport.

Another inference we draw is that the instrument for determining perceived accessibility, and how easy it is to live one's life with the help of public transport, also has the ability to differentiate between various groups in society. Conversely, the preconditions, as in the objective accessibility, are the same for all the participants in our study. 


\subsection{Conclusions}

The main point emerging from our analyses is that perceived quality of the transport mode is an important driver of perceived accessibility along with safety, frequency of use, and age. Knowledge of the drivers of perceived accessibility will be useful when planning for the inclusive and sustainable transport system we will be dependent on in the near future.

Another conclusion is that the instrument for determining perceived accessibility also has the ability to differentiate between groups. This point out its usefulness compared to objective measurements of accessibility, where no consideration is given to individual differences within, for instance, a certain neighborhood. This also strengthens the given need of a complementary, subjective measure of accessibility not only for accessibility research per se, but it may also be useful for discovering groups of people in risk of social exclusion. For instance, our results suggest that it is not only the elderly that report lower levels of perceived accessibility, but rather, people in their thirties seem to be the group experiencing the lowest perceived accessibility in public transport, indicating that if public transport was the only alternative for this group they could be a target for social exclusion.

Our findings of the mediating role of safety in the relationship between perceived quality and perceived accessibility strengthens the role of emotional evaluations as intermediate mechanisms between input and outcome (as a part of an experience). In future studies on perceived accessibility, the emotional aspects ought to be highlighted in order for researchers to determine how important they are in this area.

\subsection{Policy Implications}

Usable and comparable methods are sought in order to boost policy progress. The quantifiable operationalization of perceived accessibility paves the way for social inclusion policy integration on multiple levels since it will not discriminate against certain groups if we use it for a representative or random sample of the population. The leap toward actually using knowledge of social research in transport planning becomes shorter when our ability to evaluate accessibility improves. We argue that, by means of listening to those who use the system, perceived accessibility can help us improve social inclusion and subjective well-being. However, we need to examine accessibility further in order to explain what drives it and how it differentiates between groups. Also, we need to compare the results of perceived accessibility with accessibility as measured by objective measures, to search for discrepancies and areas where accessibility needs improvements in order to minimize perceived social exclusion. There are a number of variables that were not measured in this study, but still have the potential to be important drivers of perceived accessibility, and thus indirectly also of social inclusion. Previous research mentions, for instance, costs (fares), socioeconomic status, and area of residence.

The findings of the present and other studies (Lotfi \& Koohsari, 2009), e.g. that quality and feelings of safety have measurable effects on perceived accessibility, should be a reminder that subjective experiences may be as important as objective indicators when planning and designing socially inclusive transport systems. For many people, being able to live the life they want, e.g. experiencing ease of doing daily activities and having access to preferred activities, may be equally important for social inclusion. This insight is particularly significant to convey to the policy makers who are responsible for providing an attractive and accessible transport system.

\subsection{Future Research}

This research has investigated the role of perceived quality of a certain transport mode (bus) in the experience of actual travelers, on perceived accessibility. It is reasonable to assume that greater understanding will be reached when we can investigate perceived accessibility from the experience of non-travelers, and within other sustainable travel modes, or combinations of travel modes. An interesting approach would be comparative studies on perceived accessibility between different areas with different level of objective accessibility, between different groups of people or between cultures. Especially interesting is the unexpected findings that people in their thirties experience lower accessibility than other groups of users, even the elderly. Another approach with implications for social inclusion would be to compare our measure of perceived accessibility to (other) measures of social inclusion or social exclusion.

\section{Acknowledgements}

Financial support was obtained through grant 201405335 from the Swedish Governmental Agency for Innovation Systems.

\section{Conflict of Interests}

The authors declare no conflict of interests.

\section{References}

Banister, D. (2008). The sustainable mobility paradigm. Transport Policy, 15(2), 73-80.

Bates, J., Polak, J., Jones, P., \& Cook, A. (2001). The valuation of reliability for personal travel. Transportation Research Part E: Logistics and Transportation Review, 37(2), 191-229. 
Bekiaris, E., \& Gaitanidou, E. (2012). Research roadmap towards an accessible public transport system for all. Transport Research Arena 2012, 48, 1274-1283. doi:10.1016/j.sbspro.2012.06.1103

Berg, J., \& Levin, L. (2011). Äldres vardagliga resor: Val av färdmedel och erfarenheter av kollektivtrafik. Linköping, Sweden, VTI.

Budd, J. W., \& Mumford, K. A. (2006). Family-friendly work practices in britain: Availability and perceived accessibility. Human Resource Management, 45(1), 23-42. doi:10.1002/hrm.20091

Byrne, B. M. (2010). Structural equation modeling with AMOS (2nd ed.). London: Routledge.

Curl, A., Nelson, J. D., \& Anable, J. (2011). Does accessibility planning address what matters? A review of current practice and practitioner perspectives. Research in Transportation Business \& Management, 2, 3-11.

Currie, G., \& Stanley, J. (2008). Investigating links between social capital and public transport. Transport Reviews, 28(4), 529-547.

de Oña, J., de Oña, R., Eboli, L., \& Mazzulla, G. (2013). Perceived service quality in bus transit service: A structural equation approach. Transport Policy, 29, 219-226.

doi:http://dx.doi.org/10.1016/j.tranpol.2013.07.001

De Vos, J., Schwanen, T., Van Acker, V., \& Witlox, F. (2013). Travel and subjective well-being: A focus on findings, methods and future research needs. Transport Reviews, 33(4), 421-442. doi:10.1080/014 41647.2013.815665

dell'Olio, L., Ibeas, A., Cecín, P., \& dell'Olio, F. (2011). Willingness to pay for improving service quality in a multimodal area. Transportation Research Part C: Emerging Technologies, 19(6), 1060-1070.

Farrington, J. (2007). The new narrative of accessibility: Its potential contribution to discourses in (transport) geography. Journal of Transport Geography, 15(5), 319-330. doi:10.1016/j.trangeo.2006.11.007

Farrington, J., \& Farrington, C. (2005). Rural accessibility, social inclusion and social justice: Towards conceptualisation. Journal of Transport Geography, 13(1), 112. doi:10.1016/j.jtrangeo.2004.10.002

Field, A. (2013). Discovering statistics using IBM SPSS statistics. London: Sage Publications.

Friman, M. (2010). Affective dimensions of the waiting experience. Transportation Research Part F: Traffic Psychology and Behaviour, 13(3), 197-205. doi: http://dx.doi.org.bibproxy.kau.se:2048/10.1016/j.trf. 2010.04.006

Friman, M., \& Fellesson, M. (2009). Service supply and customer satisfaction in public transportation: The quality paradox. Journal of Public Transportation, 12(4), 4.

Friman, M., Fujii, S., Ettema, D., Gärling, T., \& Olsson, L. E. (2013). Psychometric analysis of the satisfaction with travel scale. Transportation Research Part A: Policy and Practice, 48, 132-145.
Friman, M., \& Gärling, T. (2001). Frequency of negative critical incidents and satisfaction with public transport services. II. Journal of Retailing and Consumer Services, 8(2), 105-114.

Geurs, K., \& Ritsema van Eck, J. (2001). Accessibility measures: Review and applications. Evaluation of accessibility impacts of land-use transportation scenarios, and related social and economic impact. Utrecht, the Netherlands, RIVM.

Geurs, K., \& Van Wee, B. (2004). Accessibility evaluation of land-use and transport strategies: Review and research directions. Journal of Transport Geography, 12(2), 127-140.

Gorsuch, R. L. (1997). Exploratory factor analysis: Its role in item analysis. Journal of Personality Assessment, 68(3), 532-560.

Halden, D. (2011). The use and abuse of accessibility measures in UK passenger transport planning. Research in Transportation Business and Management, 2, 12-19. doi:10.1016/j.rtbm.2011.05.001

Handy, S. L., \& Niemeier, D. A. (1997). Measuring accessibility: An exploration of issues and alternatives. Environment and Planning A, 29(7), 1175-1194.

Hayes, A. F. (2013). Introduction to mediation, moderation, and conditional process analysis: $A$ regressionbased approach. New York, USA: Guilford Press.

Hensher, D. A., Stopher, P., \& Bullock, P. (2003). Service quality: Developing a service quality index in the provision of commercial bus contracts. Transportation Research Part A: Policy and Practice, 37(6), 499-517.

Hui, V., \& Habib, K. N. (2014). An investigation of transport-related social exclusion of the at-risk community (homeless people) in Toronto, Canada. Paper presented at the Transportation Research Board 93rd Annual Meeting, Washington DC.

Kenyon, S. (2011). Transport and social exclusion: Access to higher education in the UK policy context. Journal of Transport Geography, 19(4), 763-771.

Kenyon, S., \& Lyons, G. (2003). The value of integrated multimodal traveller information and its potential contribution to modal change. Transportation Research Part F: Traffic Psychology and Behaviour, 6(1), 1-21. doi:http://dx.doi.org/10.1016/S1369-8478(02) 00035-9

Kryvobokov, M., \& Bouzouina, L. (2014). Willingness to pay for accessibility under the conditions of residential segregation. International Journal of Strategic Property Management, 18(2), 101-115.

Lättman, K., Olsson, L., E, \& Friman, M. (2015). Development and test of the perceived accessibility scale (PAC) in public transport. Manuscript submitted for publication.

Lotfi, S., \& Koohsari, M. J. (2009). Analyzing accessibility dimension of urban quality of life: Where urban designers face duality between subjective and objective reading of place. Social Indicators Research, 94(3), 417-435. 
Loukaitou-Sideris, A. (2009). How to ease women's fear of transportation environments: Case studies and best practices. ( No. FHWA-CA-MTI-09-2611).

Lucas, K. (2012). Transport and social exclusion: Where are we now? Transport Policy, 20, 105-113.

Lyubomirsky, S., Sheldon, K. M., \& Schkade, D. (2005). Pursuing happiness: The architecture of sustainable change. Review of General Psychology, 9(2), 111-153.

Martens, K. (2012). Priority setting for an inclusive transportation system. Paper presented at the 92th Annual Meeting Transportation Research Board, Washington DC.

Olsson, L. E., Gärling, T., Ettema, D., Friman, M., \& Fujii, S. (2013). Happiness and satisfaction with work commute. Social Indicators Research, 111(1), 255263. doi:10.1007/s11205-012-0003-2

Parkhurst, G., \& Meek, S. (2014). The effectiveness of park-and-ride as a policy measure for more sustainable mobility. Transport and sustainability, 5(5), 185211. doi:10.1108/S2044-994120140000005020

Preston, J., \& Rajé, F. (2007). Accessibility, mobility and transport-related social exclusion. Journal of Transport Geography, 15(3), 151-160. doi:10.1016/ j.jtrangeo.2006.05.002

Qviström, M. (2015). Putting accessibility in place: A relational reading of accessibility in policies for transitoriented development. Geoforum, 58, 166-173.

Redman, L., Friman, M., Gärling, T., \& Hartig, T. (2013). Quality attributes of public transport that attract car users: A research review. Transport Policy, 25, 119127.
Sen, A. (2000). Social exclusion: Concept, application, and scrutiny. (Social Development Papers No. 1). Manila, Philippines: Asian Development Bank.

Stanley, J., Stanley, J., Vella-Brodrick, D., \& Currie, G. (2010). The place of transport in facilitating social inclusion via the mediating influence of social capital. Research in Transportation Economics, 29(1), 280286.

Stanley, J., \& Vella-Brodrick, D. (2009). The usefulness of social exclusion to inform social policy in transport. Transport Policy, 16(3), 90-96. doi:10.1016/j.tranpol. 2009.02.003

Sundling, C., Berglund, B., Nilsson, M. E., Emardson, R., \& Pendrill, L. R. (2014). Overall accessibility to traveling by rail for the elderly with and without functional limitations: The whole-trip perspective. International Journal of Environmental Research and Public Health, 11(12), 12938-12968.

The Social Exclusion Unit. (2004). Making the connections: transport and social exclusion. (Final report). London: ODPM Publications.

United Nations. (2015). Adoption of the paris agreement (FCCC/CP/2015/L.9/rev. 1). Paris: United Nations.

van Wee, B., \& Geurs, K. (2011). Discussing equity and social exclusion in accessibility evaluations. European Journal of Transport and Infrastructure Research, 11(4), 350-367.

Warner, R. M. (2008). Applied statistics, from bivariate through multivariate techniques. Los Angeles: Sage Publications Ltd.

\section{About the Authors}

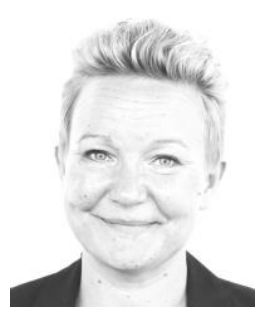

Katrin Lättman is a PhD student in psychology at Karlstad University since 2014. She is a part of the Service and Market Oriented Transport Research Group (SAMOT) at the multidisciplinary Service Research Center (CTF) in Karlstad. Katrin's thesis focuses on introducing and exploring perceived accessibility and related social outcomes in sustainable transport.

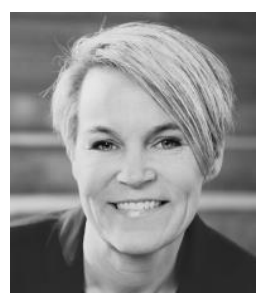

Margareta Friman is professor in psychology and director of the Service and Market Oriented Transport Research Group (SAMOT), Karlstad University, Sweden. Her research focus on satisfaction with travel, service quality, soft transport policy measures, and wellbeing. Her articles have been published in international journals in psychology, environmental studies, economics, and transportation. She is associate editor for the Frontiers in Psychology's section on environmental psychology.

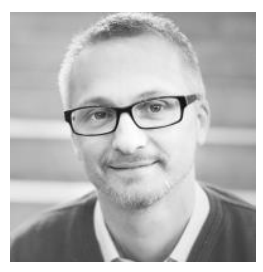

Lars E. Olsson graduated in 2007 from Göteborg University with a Ph.D. in Psychology of decision making. He is now Associate Professor of Psychology at Karlstad University, Sweden. Lars has published research in the areas of sustainability, environmental behavior, consumer experiences, accessibility, travel behavior and well-being. His articles have been published in international journals in psychology, environmental studies, economics, and transportation. 